\title{
Development of a Theoretical Framework to Investigate Alignment of Big Data in Healthcare through a Social Representation Lens
}

\author{
Kasuni Weerasinghe \\ Massey University \\ New Zealand \\ w.m.k.g.weerasinghe@massey.ac.nz
}

\section{David Pauleen}

Massey University

New Zealand

\section{Shane Scahill}

Massey University

New Zealand

\section{Nazim Taskin}

Massey University

New Zealand

\section{Abstract}

The aim of this paper is to develop a theoretical framework grounded in the literature, which can be used to explore the influence of big data on business-IT alignment in the healthcare context. Increasingly the availability of information systems in healthcare delivery and service management results in massive amounts of complex data that have the $3 \mathrm{~V}$ characteristics of big data (i.e. volume, variety, velocity). Use of big-healthcare-data has been identified as bringing significant benefits to the healthcare sector from improved decision making through to population health analysis. Although the technical dynamics around big data such as analytics and infrastructure requirements are extensively researched, less attention has been given to social dynamics such as peoples' experience, understanding and perceived usefulness of this data. To address this gap, the paper uses social representation theory as a methodological lens to develop a theoretical framework to study the social dynamics around big data and its use in the healthcare context. The selected case for this development is the New Zealand healthcare sector and an approach using multi-level macro, meso, and micro analysis is taken. Use of social representation theory as a methodological lens to develop a theoretical framework is a novel approach. Such a theoretical framework will be useful as a foundation for carrying out on-going empirical research on big data to understand its influence on business-IT alignment in the healthcare context.

Keywords: big data, healthcare, business-IT alignment, social representation theory, New Zealand healthcare, healthcare information systems.

\section{Introduction}

The growing use of information systems (IS) in the healthcare sector, alongside increasing patient populations, diseases and medication, is generating enormous amounts of unstructured and complex data that have the characteristics of 'big data' (Ward et al. 2014, 
Wyber et al. 2015). Big data is commonly known for its ' $3 V^{\prime}$ ' characteristics: volume (large in size), variety (many different types of data), and velocity (availability of data in near real-time) (McAfee and Brynjolfsson 2012). The analysis of big data, also known as 'big data analytics' is central to a revolutionary change in the business world (Davenport 2013). Until recent times data driven approaches in healthcare to make use of large volumes of complex data were considered difficult, if not impossible, because available technology was not mature enough to handle such data (Wyber et al. 2015). However, recent technological developments have opened promising avenues for healthcare to make use of big-healthcare-data for more effective healthcare management and delivery (Mace 2014).

As opposed to companies born in the digital era, traditional businesses face a greater challenge in integrating big data into their existing information technology (IT) ecosystems (Davenport and Dyché 2013). Implementing big data capabilities in traditional businesses like healthcare requires the management of change in the socio-technical aspects of an organisation such as: analytics platforms, IT architecture, IT infrastructure, security measures, required expertise and organisational structure. Within the healthcare sector, change is identified as a key factor that influences business-IT alignment (Bush et al. 2009). The importance of aligning uses of big data with clear business objectives has been acknowledged (Bean and Kiron 2013, Watson 2014). However, no alignment studies could be found in the literature which investigate the influence of big data analytics on business-IT alignment in either the business or wider healthcare literatures.

Furthermore, as a recent IT phenomenon, big data research shows a bias towards understanding technical dynamics and as such social dynamics around big data use have been largely ignored, and are not adequately researched (Shin 2015). Business-IT alignment can be examined through four dimensions: (i) strategic, (ii) structural (formal and informal), (iii) social, and (iv) cultural (Chan and Reich 2007). As the least studied and most suitable to investigate, social dynamics - the social dimension of alignment - is posited in this paper to be the ideal platform to support the investigation of the social dynamics associated with the big data construct.

Healthcare systems differ from country to country; the selected case context for the development of the framework discussed in this paper is the New Zealand healthcare system. When studying complex systems such as healthcare, which are composed of different components, structural divisions, organisations, and actors it is useful to categorise the system into macro, meso and micro (MMM) levels (Dopfer et al. 2004). For this study, we use the MMM conceptualisation discussed for the New Zealand healthcare system by Scahill (2012): macro - policy setting organisations, meso - funders and planners, and micro - service providers. Based on the findings from the literature on big data, business-IT alignment and healthcare, this paper discusses development of a framework that can be used to investigate the influence of big data on business-IT alignment in this context.

Social Representation Theory (SRT) (Moscovici 1963) is used as a methodological lens that guides the development of the theoretical framework (see Figure 1). SRT provides a holistic stance allowing us to understand how individuals co-construct representations within a social group when new situations emerge (Andersén and Andersén 2014). Representations are influenced by the pressure, opinions, social negotiation and collective sense-making of a group (Dulipovici and Robey 2013). Studying social representations brings methodological direction to a study and is therefore appropriate to be applied to IS/IT research (Gal and Berente 2008). 
Based on SRT, MMM levels are identified as social groups, which could have different representations of big data and thus impact alignment in different ways. Sub-groups such as organisations, departments or project teams within these levels are anticipated.

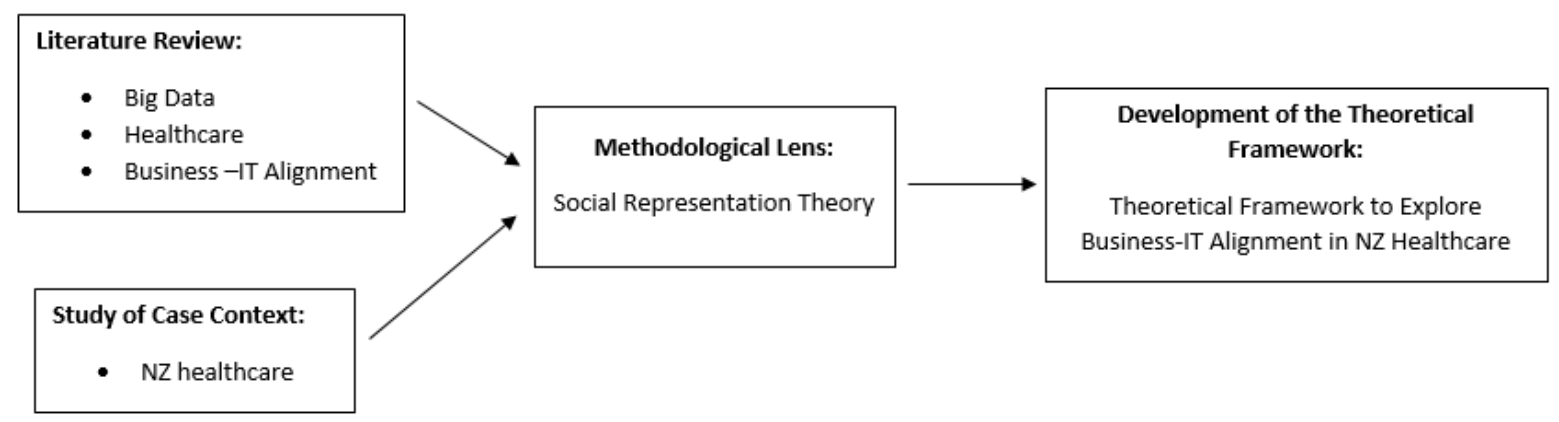

Figure 1: Use of methodological lens for the development of a theoretical framework

The term 'methodological lens' refers to the use of SRT as the methodology that guides the development of a theoretical framework (see Figure 1). The use of SRT allows not only the study of social dynamics but it also informs the structure of the theoretical framework in terms of what is to be explored and how this needs to be studied. In this manner SRT acts as a methodological lens as opposed to a theoretical lens. SRT has been used as a theoretical lens in past research (e.g. Dulipovici and Robey 2013, Gal and Berente 2008) but the authors are not aware of literature outlining the use of SRT as a methodological lens in developing a theoretical framework.

This paper discusses the development of a theoretical framework to study the influence of big data on business-IT alignment based on the New Zealand healthcare context. The process of developing such a framework could be applied to healthcare systems in other countries. Moreover, such frameworks can then be used as the basis for empirical studies which aim to develop theory.

In the following sections, we discuss the literature around big data, business-IT alignment and healthcare, highlighting the identified gaps, while SRT is discussed separately. A description of the NZ healthcare system is provided as the case under study. The aim of this paper is to posit a framework grounded in the appropriate literature, which will later be used to explore the influence of big data within the healthcare sector.

\section{Literature Review}

In this section we review the relevant literature on big data, the healthcare sector, and business-IT alignment to identify the gaps and build a foundation for the theoretical framework.

\subsection{Big data}

Based on past literature we define big data as enormous amounts of structured, unstructured and complex data produced by a wide range of computer applications (Groves et al. 2013, Kacfah Emani et al. 2015, Shin 2015, Wang and Huang 2015). Phrases such as "massive amounts of data", "enormous growth of data" and "large data sets" are typically seen within the literature as defining big data (Chen et al. 2014, Eynon 2013, Shin 2015). 
Three characteristics, known as the $3 \mathrm{~V}^{\prime} \mathrm{s}$ - volume, variety and velocity - are generally used to define big data and distinguish it from standard data (McAfee and Brynjolfsson 2012, Russom 2011). According to Gartner (2013, para1). big data is "high-volume, high-velocity and/or highvariety information assets that demand cost-effective, innovative forms of information processing that enable enhanced insight, decision making, and process automation". Watson (2014), McAfee and Brynjolfsson (2012), and Russom (2011) also characterise big data using these $3 V^{\prime}$ 's. Two additional V's - value and veracity - have also been identified, extending the characteristics of big data to 5V's (Kacfah Emani et al. 2015, Saporito 2013, Sathi 2012). Based on the $5 \mathrm{~V}$ characteristics Kacfah Emani et al. $(2015$, p72) state "dealing effectively with big data requires one to create value against the volume, variety and veracity of data while it is still in motion (velocity), not just after it is at rest".

"Analytics" is an umbrella term for all data analysis applications (Watson 2014, p1250) and refers to the use of tools to analyse data, not necessarily big data. In the business context, big data and analytics are often discussed together; they are sometimes even confused with each other with the terms being used interchangeably (McAfee and Brynjolfsson 2012). Simply collecting and storing big data creates no value unless analytics is performed to make sense of this data to improve decision making within a business (Watson 2014). However traditional analytic capabilities are not sufficient to process big data. Much more advanced infrastructure and analytical techniques are needed to glean insight from data that is high in volume, variety and velocity (Kacfah Emani et al. 2015).

Big data or big data analytics "is not a single out-of-the-box product" (Loshin 2013, p21). Making effective use of big data demands a specific combination of tools, techniques, and skills. Companies that were born in the internet era, such as Google, Facebook and eBay were built around big data (Davenport and Dyché 2013), thus these companies possess the capabilities to manage and make use of it. With technological advancements and the commercialisation of the internet, companies that existed before the internet era (deemed traditional businesses) are also looking into opportunities to develop their businesses by effectively using big data (Bholat 2015, Chawla and Davis 2013, Davenport and Dyché 2013, Dhawan et al. 2014).

To integrate big data, traditional businesses will need to consider making changes to their existing IT ecosystem. They will not only be working with big data but also with standard small datasets. Their Hadoop ${ }^{1}$ clusters may run along with their IBM mainframes; big data analytics will be used to complement traditional analytics; their data scientists will be working together with quantitative analysts (Davenport and Dyché 2013). Therefore, it is likely to be a challenge for traditional businesses to integrate the new (implementation of big data analytics) with the known (traditional data technologies in the IT ecosystem) (Bean and Kiron 2013, Davenport and Dyché 2013). In a traditional business it is expected that the use of big data would be associated with a wide range of social and technical aspects.

Technical dynamics (technology requirements of big data, challenges and opportunities of big data analytics and so forth) towards big data implementations have been extensively researched (e.g. Chen et al. 2014, Davenport 2013, Dhawan et al. 2014, Jagadish et al. 2014). As a technology revolution itself, it is fair to say that big data research often shows a bias toward

${ }^{1}$ Hadoop is an open source software framework for distributed storage and distributed processing of large data sets 
technical dynamics. Due to this bias adequate research has not yet investigated the associated social dynamics surrounding big data and its use (Shin 2015, Shin and Choi, 2015). In this paper, social dynamics refer to the users' understanding, commitment, and perceived value of big data, within a given context.

Among the scarce research that has been found exploring these humanistic factors in relation to big data analytics implementations, Shin (2015) extended the Unified Technology Acceptance and Usage Theory (UTAUT) with characteristics such as perceived usefulness and perceived ease of use extracted from the Technology Acceptance Model (TAM). Shin used this model to test the normalisation process of big data in Korean society. In his research Shin (2015) discovered that big data implementations should be user centric and driven by the requirements of end-users. However, more research is needed to investigate the influence of social dynamics when implementing big data analytics in the traditional business context, because utilisation and management of big data is equally complex.

Traditional businesses should not implement big data just to be "trendy", but rather clear goals must drive the strategy and process (Loshin 2013). A study undertaken by NewVantage Partners (2012) with Fortune 500 companies and federal agency leaders identified that business-IT alignment is crucial for the success of big data implementation. Business-IT alignment is achieved through business and technology (big data analytics) working together in harmony with proper understanding of business objectives and big data capabilities (Bean and Kiron 2013, Loshin 2013). Although the existing literature highlights the importance of business-IT alignment, studies investigating the influence of big data on business-IT alignment have not been found.

\subsection{Business-IT alignment}

For the past 30 years, alignment has been a major concern for IT practitioners and company executives (Kappelman et al. 2013). Similarly, for the past few decades many researchers have explored the importance of business-IT alignment in various business domains (e.g. Drazin and Van De Ven 1985, Dulipovici and Robey 2013, Henderson and Venkatraman 1992, Luftman 1996, Sabherwal and Chan 2001). And therefore, alignment has remained one of the dominant fields of IS research through the years (Chan and Reich 2007, Sousa and Machado 2014).

Cognates for "alignment" include terms such as fit, coherence, harmony, match, integration, congruence, relationship, gestalt, synergy and linkage. These all refer to the degree of fit between business strategy, organisational structure, IT strategy and IT infrastructure (Chan and Reich 2007, Henderson and Venkatraman 1993, Luftman 1996). Researchers who study alignment typically study the fit between two or more of these four domains (Henderson and Venkatraman 1992). Grounded in the literature, our definition of alignment refers to how well technology is utilised to bring value to a business. In the context of big data, this definition can be extended to describe how well technology is realised to make sense out of big data to create value. Creating value in the business context signifies achievement of business goals and objectives.

Over 30 years of research on alignment has led to conceptualising it in numerous ways. As such, Henderson and Venkatraman (1992) proposed the Strategic Alignment Model (SAM) to study this phenomenon. Their paper explores alignment between the domains of business strategy, business structure, IT strategy and IT structure. They identify three types of 
alignment: bivariate fit, cross-domain alignment and strategic alignment. Bivariate fit in the SAM model refers to investigation of alignment at any two domains of the model. Crossdomain alignment explains alignment across three of these domains. The third and most complex type of alignment defined in the SAM model is strategic alignment, which refers to giving "simultaneous or concurrent attention to all four domains" (Henderson \& Venkatraman, 1992, p. 20). Reich and Benbasat (1996) conceptualise studying business-IT alignment through two dimensions: social and intellectual. Chan and Reich (2007), grounded in past alignment literature, identify a number of different dimensions of business-IT alignment including: strategic/intellectual, structural (formal/informal), social and cultural. Strategic/ intellectual dimension of alignment looks at fit between business strategy and IT strategy. Structural dimension investigates the relationship between an organisation's structure and its IT. The social dimension is applied to understand how IT is perceived by different players within the organisation or the unit under study. The cultural dimension is the degree of agreement between the IT approach and the organisational culture. Chan and Reich (2007) also identified different levels of alignment as: organisational, operational, project, and individual. Although different, these conceptualisations seem to share similar characteristics, i.e. the social dimension has strong ties with the individual level (Chan and Reich 2007).

As discussed above, research on big data shows a lack of empirical studies on the social dynamics associated with big data implementations. The ideal dimension to study social dynamics to understand alignment is the social dimension of alignment as it explores how the IT is perceived by different players at different levels of an organisation. According to Reich and Benbasat (1996, p58) the social dimension can be defined as "the level of mutual understanding of commitment to the business and IT mission, objectives and plans". Unpredictable social aspects may influence the business-IT alignment. The social dimension of alignment explores how users perceive and understand the IT implementation and how the technology is actually used (Dulipovici and Robey 2013).

Compared to the strategic/intellectual and structural dimensions of alignment, fewer studies have been carried out to investigate the social dimension of alignment. Tan and Gallupe (2006) used a cognitive approach to examine the shared understanding between business and IT executives. They studied both the commonalities ${ }^{2}$ and individualities ${ }^{3}$ among people that contributed to shared cognition in an organisation. Dulipovici and Robey (2013) applied social representation theory to explore how a Knowledge Management System (KMS) is perceived and embraced by different groups of people within an organisation and discussed how the KMS influenced business-IT alignment of the organisation.

To address the identified gaps in the literature, this paper incorporates the social dimension of alignment and examines how social dynamics may influence the alignment of big data within the traditional business setting. Healthcare is selected as the context to carry out the research as it fits well with the notion of traditional business and it is also one of the fields in which big data has been identified as being beneficial (Groves et al. 2013). This provides the basis to investigate alignment in terms of how implementation and technologies around big

\footnotetext{
${ }^{2}$ Commonalities: Similarities in individuals' cognition.

${ }^{3}$ Individualities: Differences in individuals' cognition. This reflects the diversity in values and beliefs of individuals in a team.
} 
data are perceived to be creating value and how knowledgeable actors are of the business objectives of such implementations, across a country's healthcare sector.

\subsection{Transformation of Healthcare with Information Technology}

Until recently the quality of healthcare delivery has been largely dependent on the intuition and intelligence of clinical practitioners. Healthcare services have been successfully delivered because the clinical practitioners within these systems "are bright, hard-working and wellintentioned - not because of good system designs or systematic use of data" (Celi et al. 2013, p1157). However, recent research shows that there is a growing interest in using data to aid clinical practitioners in healthcare delivery and service management (Mace 2014, Patil et al. 2014, Tormay 2015).

The global healthcare industry faces significant challenges as populations grow and age - with more chronic disease, resources are constrained and systems are under significant pressure to perform (Gauld 2009). As a result, internationally health systems have undergone major changes in the past few decades to address the call for enhanced patient care and improved outcomes (Anderson 2007, Bush et al. 2009, Pare et al. 2008, Patil et al. 2014, Sicotte et al. 2006). IT and deployment of information systems (IS) is identified as central to this transformation of healthcare systems (Bush et al. 2009). These information systems focus on improving patient care, service quality, operational efficiency and patient satisfaction (Peng et al. 2014). Such targets are achieved by reducing medical errors, streamlining clinical processes, increasing productivity and controlling healthcare costs (Anderson 2007, Kannry 2011). The information systems used across health are key in creating healthcare data.

A wide range of clinical and operational information systems have been introduced (Ward et al. 2014) and used effectively within healthcare in many developed countries (e.g. USA, New Zealand, and Canada). Based on their use, these information systems are classified into two types: (i) Clinical IS (CIS), and (ii) Administrative IS (AIS) (Menon et al. 2009).

In their classification Menon et al. (2009) identify IS assisting primary value chain activities of healthcare as clinical IS; thus, these can be identified as information systems used in healthcare delivery. These systems capture, store and analyse clinical data to provide improved services in healthcare delivery (Pare et al. 2008). Electronic health records (EHR), laboratory information management systems, picture archiving and communication systems are some examples of clinical IS (Menon et al. 2009, Ward et al. 2014). In addition to aiding professionals in clinical practice, CIS also provide information for strategic planning (Glandon et al. 2008).

Also identified as operational management systems by Glandon et al. (2008), administrative IS are used for healthcare administration and service management. These information systems are used to facilitate the secondary value chain activities (support activities) of healthcare (Menon et al. 2009). Thus, they support non-patient care activities of healthcare organisations (Glandon et al. 2008). Some examples of these information systems are human resource management systems, supply chain management systems and payroll systems, similar to those in any other organisation (Glandon et al. 2008, Menon et al. 2009, Ward et al. 2014).

In addition to these stand-alone discrete information systems, complex integrated systems that combine a variety of CIS and AIS can be found across healthcare sectors. Some examples of these integrated information systems are Hospital Information Systems (HIS) (Ahmadian et al. 2014) and General Practice Information Systems (GPIS) (Yusof et al. 2008). 


\subsubsection{Big data in Healthcare}

The increasing use of EHR and other IT deployments in healthcare is contributing to the rapid growth of healthcare data (Bates et al. 2014, Patil et al. 2014). Given population growth and the rising numbers of diseases and medications, large amounts of complex data are being generated in the healthcare sector (Wyber et al. 2015). Due to the complex nature of this sector, data generated by information systems typically have characteristics (i.e. the $3 \mathrm{~V}^{\prime}$ s) of big data. Although data with the $3 \mathrm{~V}$ characteristics of big data have been generated within the healthcare sector for some time, making use of this data in healthcare has been considered complex, if not impossible, because the available technology was not mature enough to handle such data (Wyber et al. 2015).

Recent developments of technology around big data analytics are opening up promising avenues for the healthcare sector to make use of big-healthcare-data for improved healthcare delivery (Mace 2014, Nash 2014, Tormay 2015, Wyber et al. 2015). For example, Hadoop clusters introduced as a result of the big data phenomenon can be used to store massive amounts of data in an economic fashion which was not previously possible. Additionally, the development of data science skills has produced people who are capable of making sense of large and complex datasets generated in near real time. Hence, with the recent improvements to technology, the healthcare sector is now capable of deriving accurate data (veracity) to create value through big data analytics for improved healthcare delivery (Wyber et al. 2015). Consequently, although big data is not new for healthcare, making use of big data and creating value (through big data analytics) for improved healthcare delivery and management is an innovation that healthcare sectors globally are grappling with.

Nonetheless, compared to other industries such as retail merchandising and banking, the uptake of big data in the healthcare sector has been slow and limited (Bates et al. 2014, Groves et al. 2013). On top of the complex nature of the healthcare system, resistance to change by healthcare practitioners, uncertainty of returns on capital investment, and privacy concerns are identified as possible reasons for this lag (Groves et al. 2013). However, due to increasing IT expenditure and the enormous amounts of under-utilised and complex data, the healthcare sector needs more efficient practices, research and tools to analyse big data and optimise its use (Chawla and Davis 2013, Groves et al. 2013).

Recently, developed countries have recognised the importance of big data analytics for healthcare (Prewitt 2014). An estimate by McKinsey \& Company reports that with the use of big data analytic tools and technologies for healthcare, the United States can save an extraordinary $\$ 300$ billion to $\$ 450$ billion per year (Groves et al. 2013). According to experts, harnessing big data for knowledge could have significant implications for the healthcare sector. Predicting disease outbreaks, detecting gaps in care delivery, discovering the most effective treatments, identifying patterns related to medication side effects and hospital readmissions, improving pharmaceutical research, and personalised medicine are some of the identified benefits of big data analytics for healthcare (Groves et al. 2013, Nash 2014, Tormay 2015).

Because the healthcare system falls under the category of traditional business, implementing big data analytics could transform the existing IT ecosystem of the healthcare sector. As discussed previously, research outside of the healthcare sector has recognised that big data initiatives to succeed they need to be aligned with business objectives. Thus, although the healthcare sector is interested in using big data, for such initiatives to succeed, the basis for big 
data implementation should be driven by clinical and/or administrative healthcare goals and objectives.

\section{Social Representation Theory as a Methodological Lens}

Social representation theory (SRT) is used as a methodological lens for guiding and structuring the proposed theoretical framework of this paper. By methodological lens, we mean a lens that methodologically guides development of a framework. Dulipovici and Robey (2013) applied SRT to frame the investigation of how social representation of a new Knowledge Management System (KMS) in a government agency influenced business-IT alignment. Our paper adopts their approach but extends it with the aim to develop a theoretical framework using SRT to frame the study of social dynamics associated with implementing big data analytics in the healthcare sector, in order to investigate how it may influence business-IT alignment. Use of SRT in this manner forces structure and direction upon the theoretical framework, hence acting as a methodological lens. Adopting SRT as a methodological lens allows the humanistic aspects of business-IT alignment to be considered in depth.

SRT is a theory from social psychology developed by Serge Moscovici in 1961, which provides a holistic stance to understand meaning making within social groups. Over the past 50 years, SRT has been extensively used in many different fields including social sciences, media research, organisational change, healthcare, IT implementation, and information security (e.g. Andersén and Andersén 2014, Breakwell 1993, Dulipovici and Robey 2013, Gal and Berente 2008, Nichols 1981, Vaast 2007, Wagner et al. 1999).

Representation of a phenomenon (concept, object or a situation) is the central idea of the SRT. As Moscovici (1963, p251) defines it, social representation is "the elaborating of a social object by the community for the purpose of behaving and communicating". This definition was later refined to mean that objects or concepts are constituted within a social group upon thoughts, feelings and behaviours of the actors (Wagner et al. 1999). Therefore, a representation can be characterised using three elements: (i) the object which is represented; (ii) the individual who builds the understanding; and (iii) the group to which the individual belongs (Dulipovici and Robey 2013).

Gal and Berente (2008, p134) outline SRT "as a socio-cognitive framework used to study the social production of common-sense knowledge. It offers a set of concrete conceptual tools for addressing the social context from which shared meanings emerge, and for capturing the temporal nature of socio-cognitive activity". Fundamentally, SRT denotes how individuals coconstruct representations based on common understanding of an object, idea or a concept within a social group when new situations emerge (Andersén and Andersén 2014). The representation is therefore influenced by the pressure, opinions, social negotiation and collective sense-making of the group (Dulipovici and Robey 2013). Due to these continuous social interactions, representation of the object is constantly developing.

As it provides methodological direction (Dulipovici and Robey 2013) SRT is ideal for use as a methodological lens. Reviewing studies in past IS research, Gal and Berente (2008) illustrated how such studies could make a more significant contribution if studied through SRT. Studying social representations brings not only methodological direction but also conceptual richness; therefore, it is favourable to be used for IS/IT research (Dulipovici and Robey 2013, Gal and Berente 2008). Additionally Andersén and Andersén (2014) point out that SRT is much more useful when examining situations concerning organisational change. As explained, big data 
has the potential to change many aspects of a traditional business. Hence, SRT is identified as an appropriate methodology to guide an alignment study of big data around social dynamics.

According to Moscovici (1984) the social representation process emerges through two component processes: (i) anchoring, and (ii) objectification (Dulipovici and Robey 2013). Anchoring is the symbolic classification of a new phenomenon based on past experience, common background and aspirations (Gal and Berente 2008). Anchoring will develop a common understanding of the phenomenon within the group. Through anchoring the group classifies the unfamiliar and represents it in a known arrangement (Wagner et al. 1999). Objectification supports the classification (anchoring) by mapping it with examples, images, models, methods or metaphors. It is the individual interpretation of the novel concept by each individual member of the group (Dulipovici and Robey 2013, Gal and Berente 2008). Therefore these two processes complement each other, as anchoring being a social process promotes stability, and objectification being a cognitive process prompts change (Dulipovici and Robey 2013). Consequently, social representations are continuously shaped within the social group. Figure 2 illustrates how we conceptualise this understanding of anchoring, objectification and the formation of a representation within a social group.

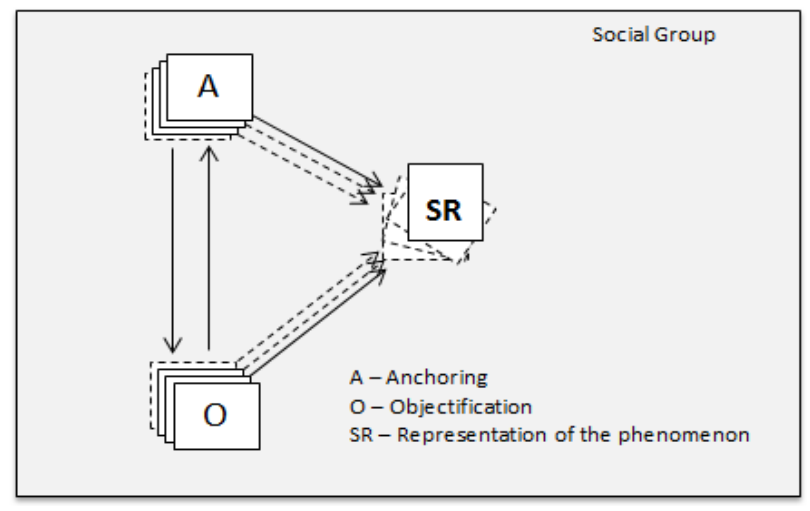

Figure 2: Conceptual illustration of SRT

Based on this, it is understood that the concept of big data and its use may be perceived within a socially constructed group through anchoring and objectification. Objectification of the notion of big data and its potential by an individual will be influenced by the individual's background, knowledge, past experience and understanding. Objectification will then influence anchoring of big data analytics within the group and result in constructing a representation.

The boundaries of a social group were broadly explained in the early definitions of SRT (Moscovici, 1963). For example, society, the community or the public was seen as the social setting that influences a social representation (Andersén and Andersén 2014). But the most recent uses of SRT divide the population into much smaller entities such as organisations (Gal and Berente 2008), and departments within organisations (Dulipovici and Robey 2013). A group may consist of two or up to an infinite number of members (Wagner et al. 1999). Moscovici (1988) defines three types of representations based on formation of social groups: (i) hegemonic, (ii) emancipated, and (iii) polemic (see Table 1). Thus as a theoretical underpinning to an empirical study of social groups, the representation to be studied can guide the selection of the group. 


\begin{tabular}{|l|l|}
\hline Hegemonic Representation & $\begin{array}{l}\text { A straightforward representation shared usually by a highly } \\
\text { structured group (e.g. city). This type of representation is already } \\
\text { established and is not produced by the group. }\end{array}$ \\
\hline Emancipated Representation & $\begin{array}{l}\text { A representation formed within a group. It could be influenced } \\
\text { by several representations of sub-groups within the group; } \\
\text { collectively the representations of sub-groups influence the } \\
\text { representation of the phenomenon within the group. }\end{array}$ \\
\hline Polemic Representation & $\begin{array}{l}\text { Mutually exclusive representations within a group due to conflict } \\
\text { and social controversy. For example Marxism is a polemic } \\
\text { representation that requires studying groups with contrasting } \\
\text { perceptions of it. }\end{array}$ \\
\hline
\end{tabular}

Table 1: Types of representations based on formation of social groups (Moscovici 1988, p221)

The phenomenon of big data analytics is not a known representation in the healthcare context; therefore, it is not a hegemonic representation. Nor is it known to have a conflicting identity with a polemic representation. Thus, based on Moscovici's definition of types of representations, we suggest that implementing big data analytics falls under the classification of an emancipated representation. It is anticipated that big data analytics could be socially constructed within a group, which may have sub-groups that contribute to the representation.

\section{The Case: New Zealand Healthcare Sector}

The healthcare systems of countries across the world operate in different ways. We have selected New Zealand (NZ) as a case to develop the theoretical framework. It is our expectation that the process of analysis of the influence of big data on alignment developed here will be applicable to other countries with similar health systems.

It is estimated that NZ spends about $10.3 \%$ of its Gross Domestic Product (GDP) on healthcare, with $31 \%$ of this spent on acute in-patient care, $34 \%$ on out-patient care, $15 \%$ on long term care, $11 \%$ on medical goods and $10 \%$ on collective services ${ }^{4}$ (OECD 2013). These services are provided to New Zealanders through a multifaceted system governed by the Ministry of Health $(\mathrm{MoH})$. The health and disability system of NZ is funded nationally, planned regionally and delivered locally (Pollock 2012). The MoH "provides whole-of-sector leadership" to the NZ healthcare system (MoH 2014, p1). High level health policy development is undertaken by the office of the Minister of Health with input from Cabinet and the government, to set strategic direction for the healthcare sector. Although the $\mathrm{MoH}$ has a greater influence in healthcare policy development, the National Health Board, Health Workforce New Zealand, the National Health Committee, and other ministerial advisory committees also support and advise the Minister (MoH 2011, 2014).

Organisations under the $\mathrm{MoH}$ are divided into 2 categories: (i) organisations that support healthcare delivery, and (ii) business units. The key organisations for healthcare delivery include the District Health Boards (DHBs), Primary Health Organisations (PHOs), Crown Entities and Agencies, National Ambulance Sector Office, Non-governmental Organisations (NGOs), Public Health Units, and professional and regulatory bodies. Apart from the organisations supporting healthcare delivery, several business units also support the $\mathrm{MoH}$

\footnotetext{
${ }^{4}$ Collective services include health education, training of health professionals, administration services and food, hygiene and water control
} 
focusing on a variety of functions and areas. These business units are composed of: (i) client insights and analytics, (ii) strategy and policy, (iii) service commissioning, (iv) protection, regulation and assurance, (v) technology and digital services, (vi) finance and performance, (vii) people and transformation, (viii) office of the Director-General, (ix) Maori leadership, (x) chief nursing officer, (xi) chief medical officer and chief pharmacy advisor as well as (xii) critical projects (MoH 2016).

Due to the inter-relationships between many different organisations, actors, and structural divisions of the NZ healthcare system this can be identified as a complex health system. Biological, socio-natural or socio-technical systems with more than three coupled components are likely to demonstrate chaotic behaviour under certain circumstances and are then identified as complex systems (Liljenström and Svedin 2005). When studying such complex systems, it is best to take an approach through the macro-meso-micro perspective of the system to compartmentalise, reduce complexity and obtain a holistic understanding (Dopfer et al. 2004). The macro-meso-micro (MMM) model can be used to conceptualise in a variety of ways dependent on the purpose of the study. Additionally, MMM levels will provide an ideal basis upon which groups can be segmented in order to study social representations.

Within the NZ healthcare sector several authors propose MMM models with slightly different but related conceptualisations. Cumming (2011) conceptualises macro as a single organisation, or a body that oversees organisation to organisation collaboration, meso as activities that promote work between organisations - e.g. clinical partnerships (Mays 2013), and micro as individual practitioners. From a slightly different view Scahill (2012) conceptualises policy setting organisations as macro, funders and planners as meso, and service provider organisations and the individuals within them as micro. Following Scahill (2012), and based on preliminary interviews, we define MMM around the use of big data as:

- Macro - Government bodies who set the strategy direction and policies that govern IT implementation, particularly implementations utilising big data fall under the macro level. Therefore, the business units as well as the $\mathrm{MoH}$ are conceptualised as the macro level bodies. In the NZ context apart from providing strategy direction the $\mathrm{MoH}$ and its business units are currently interested in initiating implementations around big data.

- $\quad$ Meso - The planners and funders meso level symbolises organisations that follow the guidelines of the macro bodies and plan to initiate (or have initiated) big data analytics. The organisations that support healthcare delivery can be mapped to the meso level (e.g. DHBs, PHOs). In the NZ context these organisations are likely to work with the government (e.g. DHBs) or have their own plans and initiate projects around big data (e.g. PHOs).

- $\quad$ Micro - Service provider organisations (e.g. hospitals, general practices) and individuals (e.g. general physicians, clinicians) within those organisations are identified as the micro level. Big data is typically generated at this level and has considerable potential to be utilised in this environment. However, it is observed that the use of big data does not solely lie with service provider organisations and their individual members. Organisations that fall under the macro and meso umbrellas are keen to make use of big-healthcare-data generated at the micro level for better planning and service delivery within the NZ health system. 
Figure 3 provides a conceptualisation of the MMM levels in NZ healthcare and how the notion of big data fits within each level.

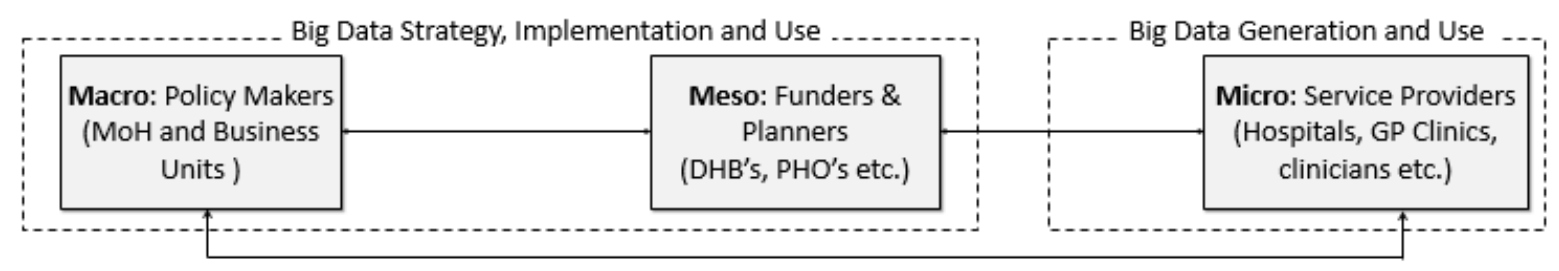

Figure 3: Conceptualisation of MMM in NZ Healthcare

Table 2 presents the elements of SRT mapped to the NZ setting. Big data is the construct of interest for the study, however depending on the group (MMM level) that is being studied at that instance, big data analytics sit within planning, implementation or use stages. The groups are mapped to the identified levels of healthcare (MMM). Individuals vary depending on the level (group) under study.

\begin{tabular}{|l|l|}
\hline Object & Big data \\
\hline Group & Macro, meso, micro levels (each level is considered as one social group) \\
\hline \multirow{3}{*}{ Individual } & $\begin{array}{l}\text { Macro - Directors, strategy level roles of MoH and business units; } \\
\text { Meso - Managers of healthcare planning and funding bodies; } \\
\text { Micro - The users of systems that generate data and analytics outcomes }\end{array}$ \\
\hline
\end{tabular}

Table 2: Elements of social representation theory for the proposed research

Although based on SRT MMM are identified as social groups to study, it may be that there are unseen sub-groups within them. These sub-groups could be influencing representation of big data within each level (group) which can only be identified through investigation. However, within each of these socially constructed groups (MMM), a social representation of big data will be uniquely constructed with or without the influence of sub-groups.

New Zealand's application of IT within the healthcare sector is among the highest in the developed world (Protti and Bowden 2010). In particular, the primary healthcare sector makes extensive use of information systems (Atalag et al. 2013). These information systems aid the clinicians in many tasks varying from administrative to management of patient care delivery as well as the associated clinical activity required to achieve this. Administrative IS are used for appointment scheduling, billing and financial administration. Clinical IS such as EHRs, ePrescriptions, eReferrals, and LIMS are used by clinicians to monitor patient history, obtain the latest medicine updates, refer patients to specialists, receive test results and so forth (Atalag et al. 2013, Pollock 2012). Therefore, CIS and AIS are effectively used across meso and micro levels of the NZ health sector.

Additionally, information systems are used in hospitals to aid clinicians in healthcare delivery and hospital management. The IS applications that are used in NZ hospitals include clinician portals, patient management systems, systems for admission management, systems for management of transfers and discharges, bed management, outpatient management, laboratory ordering and result reporting systems, digital radiology reporting systems and systems to manage specific departments such as the intensive care unit, emergency department and operating theatres (Pollock 2012). Use of such information systems rapidly generates different types of healthcare data in large volumes; therefore, it is likely to have the 
characteristics of big data (Andreu-Perez et al. 2015). A recent study undertaken by the National Institute for Health Innovation (NIHI) found that most datasets generated by information systems across the NZ healthcare sector are able to be linked through the National Health Index (NHI) and thus can be used together for large-scale data analysis (Atalag et al. 2013). This provides some evidence that NZ has taken a step towards implementing big data analytics and there is significant opportunity to further perform analyses within and across these multiple large data sets.

In addition to this, the recently revised NZ Health Strategy (Minister of Health 2016) identifies the "Smart system" as a key action area. The concept of a smart system is to collect wellorganised data from across the healthcare system as well as from other sources, to be able to achieve better health outcomes as well as to share information with other government bodies in order to achieve inter-sectorial government-wide goals (Minister of Health 2016).

Although some work around the use of big data analytics is available within the global healthcare sector, published research is very limited in the NZ context. At the time of writing Tormay (2015) and Atalag et al. (2013) are the only publications that could be found in the NZ setting which directly discuss big data in the NZ healthcare context. Neither of these two publications addresses social dynamics nor investigates business-IT alignment.

\section{Discussion: The Theoretical Framework}

\subsection{The Framework}

This section describes the theoretical framework, Big Data Alignment using SRT (BA-SRT) (see Figure 4), that has been developed from the findings in the literature on business-IT alignment, big data and the healthcare sector. SRT as the methodological lens guided the development of this framework ${ }^{5}$. As the framework was developed by considering the structure of the NZ healthcare sector it is ideal for use in that setting. The theoretical framework guides investigation of internal alignment by looking at government/business objectives and big data using the social dimension as a lens at each sector level (macro, meso and micro). SRT enforces studying social representations of big data at each level to understand alignment through a social dimension lens. Using the developed framework in a different country context may require the framework to be adapted dependent on whether it is a similar health system.

As shown in the framework (see Figure 4), although big data is generated at the micro level by the clinical interface, big data can be used across the healthcare sector for strategy and policy making, planning and funding, as well as for clinical decision making. Both macro and meso level organisations can be identified for implementing strategies and plans for successful use of big data, along with their involvement in the implementation of big data-related tools. Big data can be used for strategy and planning decisions at both macro and meso levels (e.g. population health). Therefore, the framework can be used to guide researchers looking into alignment, strategy, implementation and use of big data at the macro and meso levels. Big data generation and use can also be studied simultaneously at the micro level using this framework.

\footnotetext{
${ }^{5}$ Formation of groups and their functions are informed by the preliminary interviews conducted.
} 


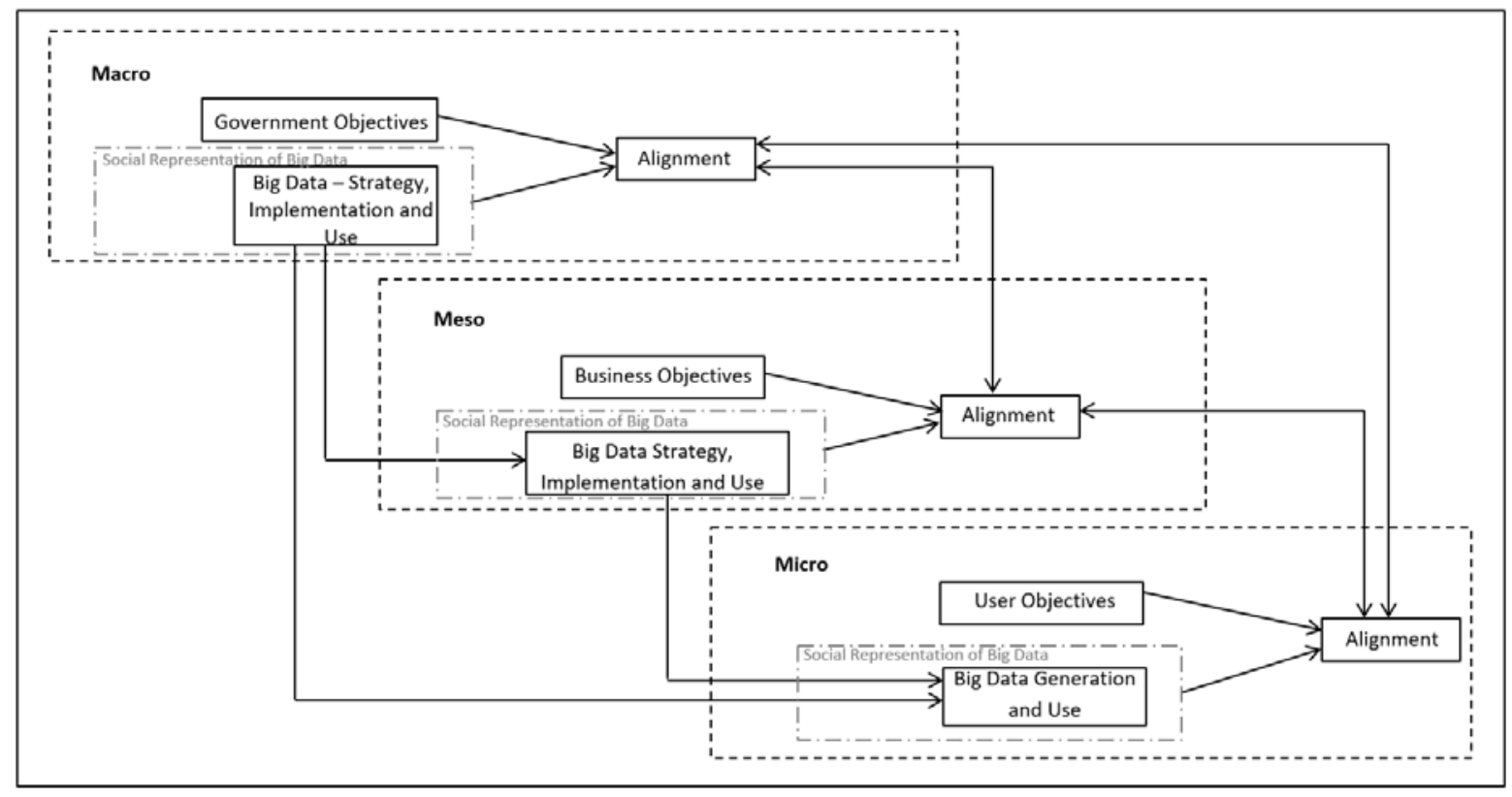

Figure 4: Big Data Alignment using SRT (BA-SRT)

\subsection{Advantages of applying this framework}

This framework can be used as a guide to explore the influence of big data on business-IT alignment using the social dimension of alignment. As Shin (2015) suggests, the use of big data involves social practices and so there needs to be more focus on integration with the social setting. Moreover, investigating the social dimension will facilitate understanding of how big data is integrated amongst the social elements of healthcare planning and delivery. The framework that has been formulated in this synthesis provides clear guidance through understanding: (i) what to study (big data strategy, implementation, generation and use at respective levels), (ii) where to study (MMM levels), and (iii) whom (Policy makers, planners and funders and clinicians) to study when researching big data in the NZ context.

Achieving and sustaining alignment is not as simple as ensuring effective formulation of big data plans and strategies and maintaining consistency with documentation, but rather the execution of IS strategies, which includes user interactions (Dulipovici and Robey 2013). Using a social dimension lens to explore business-IT alignment, we can study how strategies, plans, projects and implementations around big data are perceived by different players at different levels within the sector. This brings a focus to the human interaction with technology from a sector perspective. It is important to know how plans around big data are interpreted by different players in organisations and bodies throughout the sector. Although documented IS strategy (big data plans) could be properly aligned with the documented business strategies, the situated use could influence alignment differently. The situated use of IS involves the subjective understanding of a technological concept (i.e. big data analytics) (Dulipovici and Robey 2013). Thus it is important to look at the level of understanding and commitment to big data across healthcare organisations by key stakeholders. In order to do so, we propose that it is appropriate to look at alignment through a social dimension lens, to gain the greatest insights on the influence of big data on business-IT alignment. Our theoretical framework recommends studying social representations of big data analytics, allowing a more humanistic approach. 
The developed framework will enable researchers studying business-IT alignment to engage with all levels of the healthcare sector, from policy makers, planners, funders to practitioners. The framework therefore specifically encourages sector wide alignment, ensuring a holistic understanding of the situation of big data within the NZ healthcare sector. It is also important that alignment is present internally (within the healthcare organisations) as well as externally aligning to the government (e.g. NZ health strategy) and other funders' plans. As such we propose alignment should be studied internally within healthcare organisations as well as externally across the sector. Given the strategic refocus of the NZ Health Strategy (Minister of Health 2016) on refining the health strategy to set new directions for the next 10 years, it will be beneficial to understand how the NZ healthcare sector is reacting to the notion of big data analytics and its developments.

As our framework takes a holistic view of alignment we believe it provides a sound platform for studying business-IT alignment. Given that big data is a high profile phenomenon within the healthcare context in NZ and internationally, it is important to examine the perceived effect of these big data initiatives on business-IT alignment.

\subsection{Limitations of the Framework}

An identified limitation of our theoretical framework is that it has been formulated to meet the needs of a big data study in the New Zealand healthcare context. Based on the interpretative nature of the study and the fact that social constructions will inform the findings, it is expected that this framework is not generalizable to other healthcare contexts in its current form, and this is identified as a pitfall. Countries with similar healthcare settings may wish to adopt this framework with minimal change, but for the large majority of nations this framework will require modification based on the structure of the system and how much their system differs from the New Zealand context. However, it is expected that within most developed countries where there is a structured health system in place the macro, meso and micro levels should be able to be identified.

Another identified pitfall of the developed theoretical framework is that although it encourages studying health sector wide alignment, it has not engaged the technology vendors that work within the system and alignment with these groups must be investigated in future research. In such cases, researcher will need to analyse the similarity of the external party (such as IT vendor) with an identified level (i.e. meso) and amend the framework as required.

\section{Conclusion: Implications, Recommendations and Reflections}

There is much interest in the phenomenon of big data analytics in the modern business world. The big data construct has been discussed and researched largely through technical dynamics such as analytics, security and technological infrastructure requirements. Much less research has been reported in the area of social dynamics and the influence of these dynamics on big data strategies and use: i.e. the human side of IS implementation. Therefore, research on social dynamics such as experience, perceived value and usefulness is an important contribution for contemporary big data literature and especially in the inherently complex healthcare sector. In addition to the context, the study of social dynamics is complex, particularly in the case of a construct such as big data. As such, sound planning and a theoretical foundation is required before entering the field in order to carry out an empirical study. 
In addition, in this paper we discuss the development of a theoretical framework that is founded on and grounded in the literature, which will be used to guide this research on social dynamics associated with the big data construct. SRT was used as a methodological lens to guide the development of a theoretical framework. Big data research suggests that alignment of big data to business goals and objectives is key to the success of big data initiatives. Using SRT as the methodological lens to study social dynamics, the developed framework identifies the groups to be studied and sub-groups within the groups to study. This will act as a guide to an empirical study which aims to investigate the complex nature of business-IT alignment around big data use in the NZ healthcare context.

The development of a theoretical framework to study the influence of big data on business-IT alignment through social representations has two implications: on the one hand, it forces structure and direction to study the identified gaps in the literature. On the other, it aims to investigate how social dynamics around on-going and planned big data projects influence alignment between business and IT in the healthcare context. To date, such a framework is not available and such studies have not been conducted in the New Zealand or global context.

A study using the developed theoretical framework will capture a broader view of the NZ healthcare sector and its players' understandings and perceptions that will lead to actions around big data use. Therefore, this framework and subsequent study findings has the potential to influence policy and practice. Additionally, understanding social dynamics around big data at each level outlined in the framework (macro, meso, micro) will facilitate investigation of alignment of these social dynamics across the sector levels. Because big data is a phenomenon that runs through all the sector levels (i.e. generated at the clinical interface but can be used by policy makers, planners and funders) it is important that optimal intersector alignment is achieved across the health sector. Research studies using this theoretical framework will identify the current level of inter-sector alignment between levels (macro, meso, micro) that will better inform policy makers, planners, funders as well as the practitioners of the current status of big data and its possible implications.

The use of SRT as a methodological lens is a contribution of this paper. Using theory to explain and simplify phenomena is common practice (Mintzberg 2005). In this paper, we have used theory to focus and simplify the literature into a theoretical framework, which can then be used to explain phenomena. We believe this is the first time SRT has been used in this fashion. We recommend that theories like SRT can provide methodological guidance to studies and are capable of providing a basis for the development of theoretical frameworks, which can then be used in empirical studies.

This review of the literature provides an understanding of the gaps to be filled and the direction our future study will take. However, to go a step beyond, having a methodological lens to pull literature and context together to provide a solid foundation in the form of a preliminary theoretical framework is desirable for this research.

Our theoretical framework was developed in the context of the NZ healthcare sector and generalisability will be limited. Varying degrees of modification may be required if applying this framework to other countries' healthcare contexts, dependent on how similar the systems are. Despite this, the applicability of SRT as a methodological lens to investigate social dynamics around big data in a healthcare context is a novel approach which any healthcare sector should be able to benefit from. We recommend the use of SRT to study social dynamics around big data, beyond the healthcare sector. Other government sectors, such as education 
and transportation, may be able to adopt our framework, however considering sectorial differences there may be a need for amendments. Additionally, the healthcare sector can use the developed framework to investigate the introduction of novel technological concepts with minimal change to the developed theoretical framework.

\section{References}

Ahmadian, L., Khajouei, R., Nejad, S. S., Ebrahimzadeh, M. \& Nikkar, S. E. (2014) “Prioritizing Barriers to Successful Implementation of Hospital Information Systems", Journal Of Medical Systems, 38(12):151. doi: 10.1007/s10916-014-0151-9

Andersén, J. \& Andersén, A. (2014) “Deconstructing Resistance to Organizational Change - A Social Representation Theory Approach", International Journal of Organizational Analysis, 22(3): $342-355$.

Anderson, J. G. (2007) "Social, Ethical and Legal Barriers to E-health. International Journal of Medical Informatics, 76(5-6): 480-483. doi: dx.doi.org/10.1016/j.ijmedinf.2006.09.016

Andreu-Perez, J., Poon, C. C., Merrifield, R. D., Wong, S. T. \& Yang, G.-Z. (2015) “Big Data for Health", IEEE Journal of Biomedical and Health Informatics, 19(4):1193-1208.

Atalag, K., Gu, Y. \& Pollock, M. (2013) A Stocktake of New Zealand's Healthcare Datasets. Health Informatics New Zealand Conference, Rotorua.

Bates, D. W., Saria, S., Ohno-Machado, L., Shah, A. \& Escobar, G. (2014) “Big Data In Health Care: Using Analytics To Identify And Manage High-Risk And High-Cost Patients", Health Affairs, 33(7):1123-1131. doi: 10.1377/hlthaff.2014.0041

Bean, R. \& Kiron, D. (2013) “Organizational Alignment Is Key to Big Data Success”, MIT Sloan Management Review Big Idea: Data \& Analytics, 54(3).

Bholat, D. (2015) “Big Data and Central Banks”, Quarterly Bulletin 2015 Q1, 55(1): 86-93.

Breakwell, G. M. (1993) "Social Representations and Social Identity", Papers on Social Representations, 2(3):198-217.

Bush, M., Lederer, A. L., Li, X., Palmisano, J. \& Rao, S. (2009) “The Alignment of Information Systems with Organizational Objectives and Strategies in Health Care", International Journal of Medical Informatics, 78(7):446-456.

Celi, L. A., Mark, R. G., Stone, D. J. \& Montgomery, R. A. (2013) “'Big Data' in the Intensive Care Unit. Closing the Data Loop", American Journal of Respiratory and Critical Care Medicine, 187(11):1157-1160. doi: 10.1164/rccm.201212-2311ED

Chan, Y. E. \& Reich, B. H. (2007) "IT Alignment: What Have We Learned?", Journal of Information Technology, 22(4):297-315.

Chawla, N. \& Davis, D. (2013) “Bringing Big Data to Personalized Healthcare: A PatientCentered Framework", JGIM: Journal of General Internal Medicine, 28(Suppl 3):660-665. doi: 10.1007/s11606-013-2455-8

Chen, M., Mao, S. \& Liu, Y. (2014) "Big Data: A Survey", Mobile Networks and Applications, 19(2):171-209.

Cumming, J. (2011) “Integrated Care in New Zealand", International Journal of Integrated Care, 11(Special 10th Anniversary Edition):e138. 
Davenport, T. H. (2013) "Analytics 3.0: In the New Era, Big Data Will Power Consumer Products and Services", Harvard Business Review. Available at: https://hbr.org/2013/12/analytics-30 [Accessed 10 Sep 2015]

Davenport, T. H. \& Dyché, J. (2013) "Big Data in Big companies", International Institute for Analytics, 3.

Dhawan, R., Singh, K. \& Tuteja, A. (2014) “When Big Data Goes Lean”, McKinsey Quarterly, 24(2):97-102.

Dopfer, K., Foster, J. \& Potts, J. (2004) “Micro-meso-macro", Journal of Evolutionary Economics, 14(3):263-279.

Drazin, R. \& Van De Ven, A. H. (1985) "Alternative Forms of Fit in Contingency Theory", Administrative Science Quarterly, 30(4):514-539.

Dulipovici, A. \& Robey, D. (2013) “Strategic Alignment and Misalignment of Knowledge Management Systems: A Social Representation Perspective", Journal of Management Information Systems, 29(4):103-126.

Eynon, R. (2013) “The Rise of Big Data: What Does it Mean for Education, Technology, and Media Research?", Learning, Media and Technology, 38(3):237-240.

Gal, U. \& Berente, N. (2008) “A Social Representations Perspective on Information Systems Implementation: Rethinking the Concept of 'Frames'”, Information Technology \& People, 21(2):133-154.

Gartner. (2013) IT Glossary. Available at: http://www.gartner.com/it-glossary/big-data/ [Accessed 25 Jun 2016]

Gauld, R. (2009) The New Health Policy. Open University Press, Maidenhead.

Gerow, J. E., Thatcher, J. B. \& Grover, V. (2014) “Six Types of IT-Business Strategic Alignment: An Investigation of the Constructs and their Measurement", European Journal of Information Systems, 24(5):1-27. doi: 10.1057/ejis.2014.6

Glandon, G. L., Austin, C. J., Boxerman, S. B., Smaltz, D. H., \& Slovensky, D. J. (2008) Austin and Boxerman's Information Systems for Healthcare Management. Health Administration Press, Chicago.

Groves, P., Kayyali, B., Knott, D. \& Van Kuiken, S. (2013) “The 'Big Data' Revolution in Healthcare: Accelerating Value and Innovation", McKinsey Quarterly.

Henderson, J. C. \& Venkatraman, N. (1992) "Strategic Alignment: A Model for Organizational Transformation through Information Technology", in T. A. Kochan \& M. Useem (Eds.), Transforming Organizations (pp. 97-116). Oxford University Press, New York.

Henderson, J. C. \& Venkatraman, N. (1993) "Strategic Alignment: Leveraging Information Technology for Transforming Organizations", IBM systems journal, 32(1):472-484.

Jagadish, H. V., Gehrke, J., Labrinidis, A., Papakonstantinou, Y., Patel, J. M., Ramakrishnan, R. \& Shahabi, C. (2014) "Big Data and its Technical Challenges", Communications of the ACM, 57(7):86-94.

Kacfah Emani, C., Cullot, N. \& Nicolle, C. (2015) “Understandable Big Data: A Survey", Computer Science Review, 17. doi: dx.doi.org/10.1016/j.cosrev.2015.05.002 
Kannry, J. (2011) "Effect of e-Prescribing Systems on Patient Safety", The Mount Sinai Journal Of Medicine, 78(6):827-833. doi: 10.1002/msj.20298

Kappelman, L. A., McLeon, E., Luftman, J. \& Johnson, V. (2013) “Key Issues of IT Organizations and their Leadership: The 2013 SIM IT Trends Study", MIS Quarterly Executive, 12(4):227-240.

Liljenström, H. \& Svedin, U. (2005) Micro, Meso, Macro: Addressing Complex Systems Couplings, World Scientific Publishing Company.

Loshin, D. (2013) Big Data Analytics : From Strategic Planning to Enterprise Integration with Tools, Techniques, NoSQL, and Graph. Amsterdam: Morgan Kaufmann.

Luftman, J. N. (1996) Competing in the Information Age : Strategic Alignment in Practice, Oxford University Press, New York.

Mace, S. (2014) “Big Data and the Analytics Imperative”, HealthLeaders Magazine, 17(9): 12-24.

Mays, N. (2013) Reorienting the New Zealand Health Care System to Meet the Challenge of LongTerm Conditions in a Fiscally Constrained Environment. New Zealand Treasury Conference, Affording Our Future, Wellington.

McAfee, A. \& Brynjolfsson, E. (2012) “Big Data: The Management Revolution”, Harvard Business Review, 90(10):60-68.

Menon, N. M., Yaylacicegi, U. \& Cezar, A. (2009) "Differential Effects of the Two Types of Information Systems: A Hospital-Based Study", Journal of Management Information Systems, 26(1):297-316.

Minister of Health (2016) New Zealand Health Strategy: Future Direction, Ministry of Health, Wellington.

Mintzberg, H. (2005) "Developing Theory about the Development of Theory", Great Minds in Management: The Process of Theory Development, 355-372.

$\mathrm{MoH}$ (2011) Overview of the Health System. Available at: http://www.health.govt.nz/newzealand-health-system/overview-health-system_ [Accessed 20 May 2015].

MoH (2014) Briefing to the Incoming Minister 2014, Wellington.

MoH (2016) Ministry Business Units. Available at: http://www.health.govt.nz/aboutministry/ministry-business-units [Accessed 19 January 2017].

Moscovici, S. (1963) "Attitudes and Opinions", Annual Review of Psychology, 14(1):231-260.

Moscovici, S. (1984) “The Phenomenon of Social Representation”, in R. M. Farr \& S. Moscovici (Eds.), Social Representations: European Studies in Social Psychology, Cambridge University Press, Cambridge.

Moscovici, S. (1988) "Notes Towards a Description of Social Representations”, European Journal of Social Psychology, 18(3):211-250.

Nash, D. B. (2014) "Harnessing the Power of Big Data in Healthcare", American Health \& Drug Benefits, 7(2):69-70. 
NewVantage Partners (2012) Big Data Executive Survey: Themes \& Trends. Available at: http://newvantage.com/wp-content/uploads/2012/12/NVP-Big-Data-SurveyThemes-Trends.pdf [Accessed 20 November 2015]

Nichols, B. (1981) Ideology and the Image: Social Representation in the Cinema and Other Media (Vol. 256), Indiana University Press, Bloomington.

OECD (2013) Health at a Glance. Available at: http://www.oecd-ilibrary.org/ [Accessed 20 May 2016]

Pare, G., Sicotte, C., Jaana, M. \& Girouard, D. (2008) Prioritizing Clinical Information System Project Risk Factors: A Delphi Study. 41st Hawaii International Conference on System Sciences (HICSS 2008).

Patil, P., Raul, R., Shroff, R. \& Maurya, M. (2014) “Big Data in Healthcare”, International Journal of Research in Information Technology, 2(2):202-208.

Peng, G., Dey, D. \& Lahiri, A. (2014) “Healthcare IT Adoption: An Analysis of Knowledge Transfer in Socioeconomic Networks", Journal of Management Information Systems, 31(3):7-34. doi: 10.1080/07421222.2014.994672

Pollock, M. (2012) Better Information for Better Care - New Zealand's Approach to Efficient and Affordable Healthcare (White Paper), National Institute for Health Innovation (NIHI). Available at: http://www.ehealthnews.eu/download/white-papers/3028-betterinformation-for-better-care-new-zealands-approach-to-efficient-and-affordablecare [Accessed 10 November 2015].

Prewitt, E. (2014, 1 November) “Addressing the Big Challenges", HealthLeaders Magazine, 17:66.

Protti, D. \& Bowden, T. (2010) “Electronic Medical Record Adoption in New Zealand Primary Care Physician Offices", Commonwealth Fund: Issues in International Health Policy, 96.

Reich, B. H. \& Benbasat, I. (1996) “Measuring the Linkage Between Business and Information Technology Objectives", MIS Quarterly, 20(1):55-81.

Russom, P. (2011) “Big Data Analytics”, TDWI Best Practices Report, Fourth Quarter. Available at:

$\mathrm{ftp}: / / \mathrm{ftp}$. software.ibm.com/software/tw/Defining_Big_Data_through_3V_v.pdf [Accessed 10 Oct 2015]

Sabherwal, R. \& Chan, Y. E. (2001) "Alignment Between Business and IS Strategies: A Study of Prospectors, Analyzers, and Defenders", Information Systems Research, 12(1):11-33.

Saporito, P. (2013) "The 5 V's of Big Data: Value and Veracity Join Three More Crucial Attributes that Carriers Should Consider When Developing a Big Data Vision", Best's Review, 38. Available at: https://www.thefreelibrary.com/The+5+V\%27s+of+big+data\%3A+value+and+ve racity+join+three+more+crucial...-a0350676739 [Accessed 10 November 2015]

Sathi, A. (2012) Big Data Analytics: Disruptive Technologies for Changing the Game: Mc Press, Boise. 
Scahill, S. L. (2012) “The 'Way Things Are Around Here': Organisational Culture Is a Concept Missing from New Zealand Healthcare Policy, Development, Implementation, and Research", New Zealand Medical Journal (Online). Available at: http://www.nzma.org.nz/journal/read-the-journal/all-issues/2010-2019/2012/vol125-no-1348/view-scahill [Accessed 10 October 2015]

Shin, D.-H. (2015) “Demystifying Big Data: Anatomy of Big Data Developmental Process", Telecommunications Policy, 40(9):837-854.

Shin, D.-H. \& Choi, M. J. (2015) "Ecological Views of Big Data: Perspectives and Issues", Telematics and Informatics, 32(2):311-320. doi: http://dx.doi.org/10.1016/j.tele.2014.09.006

Sicotte, C., Pare, G., Moreault, M.-P. \& Paccioni, A. (2006) “A Risk Assessment of Two Interorganizational Clinical Information Systems", Journal of the American Medical Informatics Association, 13(5):557-566.

Sousa, J. L. R. \& Machado, R. J. (2014) “Sociomaterial Enactment Drive of Business/IT Alignment: From Small Data to Big Impact", Procedia Technology, 16:569-582. doi: 10.1016/j.protcy.2014.10.005

Tan, F. B. \& Gallupe, R. B. (2006) “Aligning Business and Information Systems Thinking: A Cognitive Approach", IEEE Transactions on Engineering Management, 53(2):223-237. doi: 10.1109/TEM.2006.872243

Tormay, P. (2015) “Big Data in Pharmaceutical R\&D: Creating a Sustainable R\&D Engine", Pharmaceutical Medicine - New Zealand, 29(2):87-92. doi: 10.1007/s40290-015-0090-x

Vaast, E. (2007) “Danger is in The Eye of the Beholders: Social Representations of Information Systems Security in Healthcare", The Journal of Strategic Information Systems, 16(2):130152.

Wagner, W., Duveen, G., Farr, R., Jovchelovitch, S., Lorenzi-Cioldi, F., Markova, I. \& Rose, D. (1999) “Theory and Method of Social Representations", Asian Journal of Social Psychology, 2(1):95-125.

Wang, X. \& Huang, J. Z. (2015) “Editorial: Uncertainty in Learning from Big Data”, Fuzzy Sets and Systems, 258(1):1-4. doi: 10.1016/j.fss.2014.10.010

Ward, M. J., Marsolo, K. A. \& Froehle, C. M. (2014) “Applications of Business Analytics in Healthcare", Business Horizons, 57(5):571-582. doi: 10.1016/j.bushor.2014.06.003

Watson, H. J. (2014) “Tutorial: Big Data Analytics: Concepts, Technologies, and Applications”, Communications of the Association for Information Systems, 34(1):1247-1268.

Wyber, R., Vaillancourt, S., Perry, W., Mannava, P., Folaranmi, T. \& Celi, L. A. (2015) “Big Data in Global Health: Improving Health in Low- and Middle-Income Countries", Bulletin of the World Health Organization, 93(3):203-208. doi: 10.2471/BLT.14.139022

Yusof, M. M., Kuljis, J., Papazafeiropoulou, A. \& Stergioulas, L. K. (2008) “An Evaluation Framework for Health Information Systems: Human, Organization and Technology-Fit Factors (HOT-fit)", International Journal of Medical Informatics, 77(6):386-398. 
Copyright: (C) 2018 Weerasinghe, Pauleen, Scahill \& Taskin. This is an open-access article distributed under the terms of the Creative Commons Attribution-NonCommercial 3.0 Australia License, which permits non-commercial use, distribution, and reproduction in any medium, provided the original author and AJIS are credited.

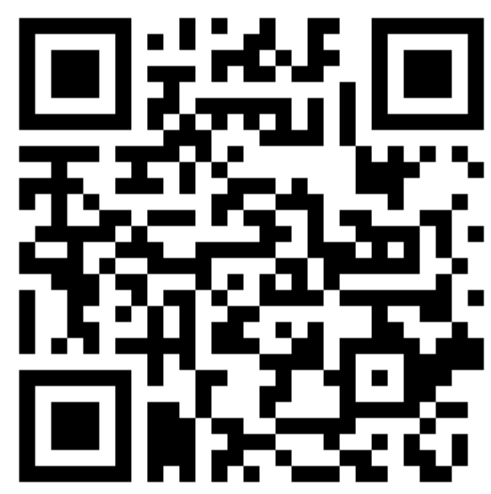

